\title{
Adsorption of nutrients by substrates for constructed wetland
}

\author{
Yuanyuan Fang ${ }^{a}$, Linghua Liu ${ }^{\mathrm{b}}$, Leixiang $\mathrm{Wu}^{\mathrm{c}}$ \\ Department of Water Environment, IWHR, Beijing 100038, China \\ afangyy21@163.com, 'lhliu@iwhr.com, 'leixiangwu@163.com
}

Keywords: adsorption, nutrients removal, mixed substrates.

\begin{abstract}
Zeolite, haydite, tire crumb, volcanic and vermiculite were selected as potential substrates of constructed wetland. This study investigates the adsorption of the mixed substrates for removing nutrients. A series of batch test experimentations was performed. The results indicate that there is an obvious advantage to zeolite on nitrogen removal and so to tire crumb on phosphorus removal when simulated sewage were treated. While the optimal combination for the removal of nutrients in five different mixed substrates was the 4th mixed substrates (haydite $25 \%$, vermiculite $25 \%$, zeolite $25 \%$, tire crumb $25 \%$ ).
\end{abstract}

\section{Introduction}

Constructed wetland is an ecological technology of sewage treatment with simple structure, convenient for operation. It's consisted of substrates, aquatic and microorganism ${ }^{[1-4]}$. Compared with the traditional sewage treatment technology, constructed wetlands are widely used which with a lot of advantages like less investment, low use cost, higher capacity in resistance to shock loading, better treatment, no secondary pollution and so on ${ }^{[5-10]}$.

The most important part of artificial wetland is substrates, which can greatly improve the effect of removing nutrient in sewage. At present, many materials have been tested, such as gravel, zeolite, haydite, shale, volcanic, slag, anthracite, coal cinder, brick, sands, sawdust, and tire crumb ${ }^{[11-16]}$. Wang ${ }^{[17]}$ studied zeolite, kaoline, mica powder on the removal of nitrogen and phosphorus in sewage. They found the adsorption capacity of zeolite on ammonia nitrogen is the largest. Liu ${ }^{[18]}$ researched the adsorption properties of shale, haydite and gravel on phosphorus. The result showed that the saturated adsorption of media follow the order shale $>$ haydite $>$ gravel. Marty Wanielista $M$ ${ }^{[19]}$ obtained that the effect of tire crumb on phosphorus is significant. From the above, it can be concluded the research on single substrate was widely studied, while the mixed of substrates was not so many. The different nature of mixed substrates not only provide a more diverse growing environment for microorganisms in constructed wetland system, but also improve the comprehensive removal of contaminants by different substrates on pollutants removal ${ }^{[20]}$. However, it's significance to study on the mixed substrates of removing nutrient.

The main objective of this study is to investigate the removal efficiency of mixed substrates (zeolite, haydite, tire crumb, volcanic, vermiculite) on nitrogen and phosphorus from batch test experiment by single media and mixed media to provide a reasonable basis on selecting and optimizing substrates of aritificial wetlands.

\section{Materials and Methods}

\subsection{Materials and Equipments}

Zeolite, haydite, tire crumb, volcanic and vermiculite were chosen in the study. Four kinds of the substrates (except tire crumb) were taken from Lingshou, a county in Hebei province. The tire crumb was smashed by waste tires. The size of the substrates was $2-4 \mathrm{~mm}$. To remove the dust, the substrates were washed by tap water and then oven dried.

The stock solution of ammonia nitrogen $\left(\mathrm{NH}_{3}-\mathrm{N}\right)$, nitrate nitrogen $\left(\mathrm{NO}_{3}-\mathrm{N}\right)$, and total phosphorus (TP) were prepared from $\mathrm{NH}_{4} \mathrm{Cl}, \mathrm{KNO}_{3}, \mathrm{KH}_{2} \mathrm{PO}_{4}$ respectively. New solutions were prepared before each experiment to avoid any possible contamination. The concentration of stock 
solution was showed in Table 1.

Table.1 Concentration of stock solution

\begin{tabular}{ccccc}
\hline & $\mathrm{TN}$ & $\mathrm{NH}_{3}-\mathrm{N}$ & $\mathrm{NO}_{3}-\mathrm{N}$ & $\mathrm{TP}$ \\
\hline Concentration(mg/L) & $3.09 \sim 3.50$ & $1.48 \sim 1.60$ & $1.05 \sim 1.63$ & $0.55 \sim 0.74$ \\
\hline
\end{tabular}

\subsection{Batch Test Experimentations}

Batch Test experimentation were carried out for single substrate and mixed substrates. First, 30 gram of dry substrate (zeolite, haydite, tire crumb, volcanic or vermiculite) was poured into a $500 \mathrm{ml}$ Erlenmeyer flask and $300 \mathrm{ml}$ of water sample was taken into the flask. The top of each Erlenmeyer flask was wrapped using parafilm to avoid evaporation. The flask which contains water sample and substrates were kept on a shaking platform with 125 revolutions per minute at room temperature $\left(23 \pm 2^{\circ} \mathrm{C}\right)$. The samples are taken off of the shaking platform at times $1 \mathrm{hr}, 4 \mathrm{hr}, 8 \mathrm{hr}, 12 \mathrm{hr}, 24 \mathrm{hr}, 48 \mathrm{hr}$, 72hr, 96hr. All samples were filtered using a $4.5 \mu \mathrm{m}$ filter membrane. Then the nutrient concentration in water samples was tested. Next, mixed substrates were performed. In this study, 5 initial mixed that consist of the five substrates were tested. Table 2 shows a list of the initial mixed substrates.

Table.2 Mixed ratio of substrates (Quality)

\begin{tabular}{cccccc}
\hline Numbered & haydite & volcanic & zeolite & tire crumb & vermiculite \\
\hline 1 & $50 \%$ & $50 \%$ & & & \\
2 & $50 \%$ & $25 \%$ & $25 \%$ & & \\
3 & $50 \%$ & $25 \%$ & & $25 \%$ & \\
4 & $25 \%$ & $25 \%$ & $25 \%$ & $25 \%$ & \\
5 & $25 \%$ & $25 \%$ & $25 \%$ & & $25 \%$ \\
\hline
\end{tabular}

\subsection{Methods for Batch Test Experimentation}

The water samples were tested for total nitrogen $(\mathrm{TN})$, ammonia nitrogen $\left(\mathrm{NH}_{3}-\mathrm{N}\right)$, nitrate nitrogen $\left(\mathrm{NO}_{3}-\mathrm{N}\right)$, and total phosphorus (TP) using Methods found in Table 3.

Table.3 Methods for batch test experimentations

\begin{tabular}{cccc}
\hline $\begin{array}{c}\text { Parameter of } \\
\text { concern }\end{array}$ & Methodology of Test & Specific Test & Test Range \\
\hline $\begin{array}{c}\text { Nitrogen, Total } \\
\text { Nitrogen, }\end{array}$ & Alkaline persulfate digestion method & GB11894-89 & $0.05-4 \mathrm{mg} / \mathrm{L}, \mathrm{N}$ \\
Ammonia & Nessler's reagent colorimetric & Hach Method & $0.02-2.5 \mathrm{mg} / \mathrm{L}$, \\
method & 8038 & $\mathrm{NH}_{3}-\mathrm{N}$ \\
Nitrogen, Nitrate & UV spectrophotometric & determination & HJ/T 346-2007 \\
Phosphorus, Total & Persulfate digestion method & GB11893-89 & $0.01-0.6 \mathrm{mg} / \mathrm{L}, \mathrm{L}, \mathrm{P}$ \\
\hline
\end{tabular}

\section{Results and Discussion}

\subsection{Adsorption of nutrient by different substrates}

The adsorption quantity of different substrates on the removal of nitrogenous and phosphorus is checked and shown in Figure 1. 


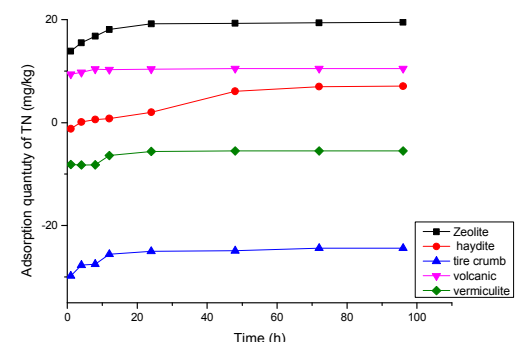

(a)

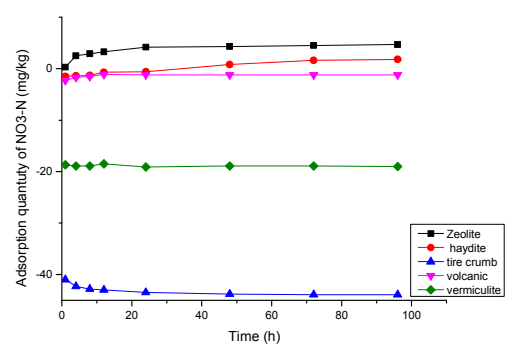

(c)

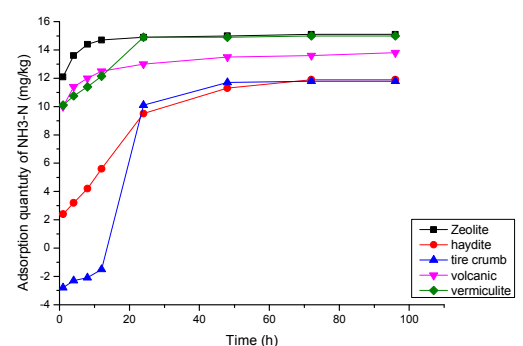

(b)

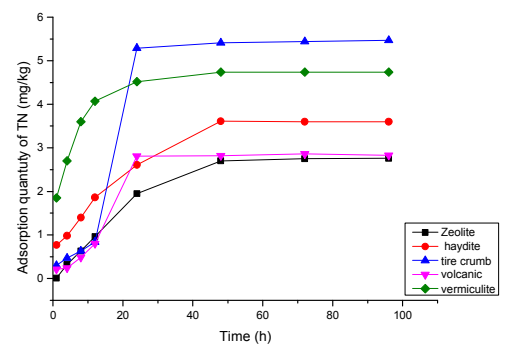

(d)

Figure.1. Adsorption time curve of nutrient

Figure 1 (a) shows that the adsorption of TN had reached balanced state at $48 \mathrm{~h}$. At this time, the adsorption quantity of zeolite was the largest one, followed by volcanic, haydite. While vermiculite and tire crumb was negative. It indicated that the concentration of water samples which had vermiculite and tire crumb increased, and the sample which had tire crumb was higher. As can be seen from Fig.1 (b), the adsorption of $\mathrm{NH}_{3}-\mathrm{N}$ had a significant effect by any substrates. Zeolite, vermiculite and volcanic had reached equilibrium state at $24 \mathrm{~h}$, while haydite and tire crumb had reached at $48 \mathrm{~h}$. The adsorption capacity of different substrates followed the order zeolite $>$ vermiculite $>$ volcanic $>$ haydite $>$ tire crumb. From Fig.1 (c), it can be concluded that the adsorption of $\mathrm{NO}_{3}-\mathrm{N}$ by each substrate were not obvious, except zeolite with a little effect. The other three substrates had negative adsorption quantity and tire crumb was the minimum, followed by vermiculite. Fig 1 (d) shows that the effect of adsorption on TP was obvious. At $24 \mathrm{~h}$, tire crumb, vermiculite, volcanic had reached balanced state, while haydite and zeolite had reached at $48 \mathrm{~h}$. The adsorption capacity of TP followed the order tire crumb $>$ vermiculite $>$ haydite $>$ volcanic $>$ zeolite. These studies revealed that the removal of nitrogen by zeolite is remarkably well, while the effect of haydite and volcanic is average. And the removal of phosphorus by tire crumb is the best in five substrates, followed by vermiculite and haydite. In batch test experimentation of mixed substrates, haydite and volcanic were selected as the foundation substrates and the other three substrates were added to find the optimal media mix.

\subsection{Removal process of nutrient by mixed substrates}

The variation of the removal rate of $\mathrm{TN}, \mathrm{NH}_{3}-\mathrm{N}$, TP by 5 groups of mixed substrates is exposed in Fig.2. The removal of $\mathrm{NO}_{3}-\mathrm{N}$ is not showed in graph as the effect of adsorption on $\mathrm{NO}_{3}-\mathrm{N}$ is not clear in single substrate experiment.

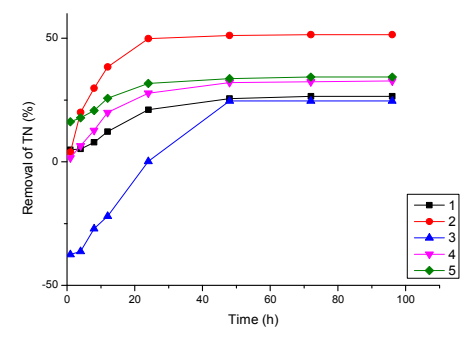

(a)

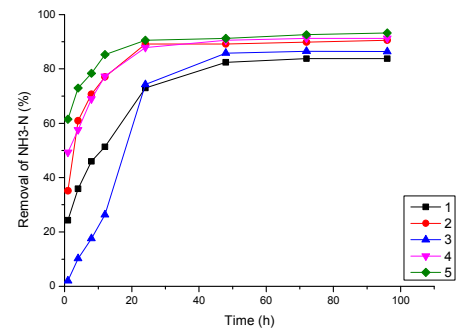

(b)

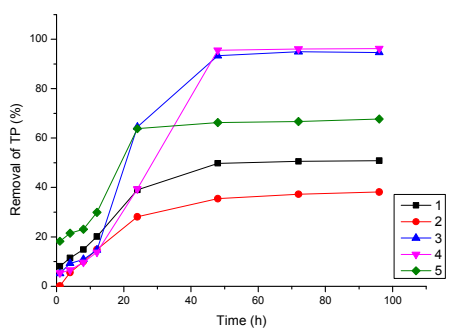

(c)

Figure.2. Changes of nitrogen removal rate of mixed substrates 
As it can be seen from Figure 2 (a), the percentage removal of total nitrogen was increased rapidly at first and then slowly increasing until reached equilibrium state. The removal of TN by No. 2 and No.5 mixed media had reached balance state at $24 \mathrm{~h}$, while the other mixed media had reached at $48 \mathrm{~h}$. At this moment, the percentage removal of TN was nearly invariable. Because zeolite was contained, the highest percentage removal of $\mathrm{TN}$ is the No.2 mixed media. Although zeolite was also found in No.4 and No.5 groups, tire crumb and vermiculite which contained in No.4 or No.5 groups weakened the effect. The removal of No.3 was negative values at $0 \sim 24$ hour due to the tire crumb. The removal rate increased and changed from negative to positive as haydite and volcanic constantly adsorb the $\mathrm{TN}$ of the samples with the increase of time. However, the adsorption of No.3 media is the least one. The percentage removal of No.1 media is slightly larger than the 3th while there is only haydite and volcanic was contained in No.1 media. In conclusion, the mixed substrate which was contained zeolite is better in removal of TN.

From Figure 2 (b), it can be concluded that each groups has a strong adsorption effect of ammonia nitrogen. The removal rates of all groups were all over $75 \%$ when reached the equilibrium state. Because zeolite was contained, the removal efficiency of No.2, No.4, No.5 mixed media increase quickly and reached equilibrium state at $24 \mathrm{~h}$, especially the No.5. The removal of No.5 is the best one while zeolite and vermiculite were both contained in. No.1 and No.3 mixed media were reached the balance state at $48 \mathrm{~h}$, and the removal rate was slightly less than the other groups.

From Figure 2 (c), it can be obtained that the removal rate of five groups of substrates on total phosphorus was increased with time increasing until reached the balance state at $48 \mathrm{~h}$. Because tire crumb was contained, the removal efficiency of No.3 and No.4 groups were greatly enhanced. However, the percentage removal was higher than other groups. Tire crumb which were contained in No.4 media changed to the same quality of vermiculite was the No.5 media. The removal rate of No. 5 media was less than No. 3 and No. 4 groups but greater than No. 1 and No. 2 groups. It illustrated the removal of TP can be increased by vermiculite, but the effect of vermiculite was not so obvious when compared with tire crumb. This result is consistent with the previous experimental. No. 2 media was mixed with haydite $(50 \%)$, volcanic $(50 \%)$, zeolite $(25 \%)$, while the effect of the three kinds of substrates was relatively weak. So No.2 media is the weakest in adsorption of TP. However, the percentage removal of No.1 media was slightly greater than No.2. In conclusion, the mixed substrate which was contained tire crumb is better in removal of TP.

3.3 Effect of removing nutrient by mixed substrates

Figure 3 shows the removal of $\mathrm{TN}, \mathrm{NH}_{3}-\mathrm{N}, \mathrm{TP}$ by five groups of substrates at equilibrium state. As can be seen, the removal rate of No.2 group on TN is $51.45 \%$ and it's the best one, the highest removal rate of $\mathrm{NH}_{3}-\mathrm{N}$ is No.5 group (93.24\%), the best removal efficiency of TP is No.4 group (96.97\%). Because zeolite was added, the removal of No.2 group (haydite $50 \%$, volcanic $25 \%$, zeolite $25 \%$ ) is better. The effect of removing TP by No.3 group (haydite $50 \%$, volcanic $25 \%$, tire crumb $25 \%$ ) is better because of tire crumb. No. 4 mixed media (haydite $25 \%$, volcanic $25 \%$, zeolite $25 \%$, tire crumb $25 \%$ ) is a combination of No. 2 and No. 3 groups. Zeolite was contained to enhance the adsorption of nitrogen and tire crumb was contained to reinforce on phosphorus adsorption. Therefore, No.4 media is the best one which on removing nutrient in five mixed groups. But the effect of removing total nitrogen not so good, it may because of tire crumb. So it can be appropriate to increase the proportion of zeolite in the mixed substrates if the content of nitrate nitrogen is higher in wastewater treatment, such as mixed with haydite $20 \%$, volcanic $20 \%$, zeolite $40 \%$, tire crumb $20 \%$ or haydite $20 \%$, volcanic $20 \%$, zeolite $45 \%$, tire crumb $15 \%$. 


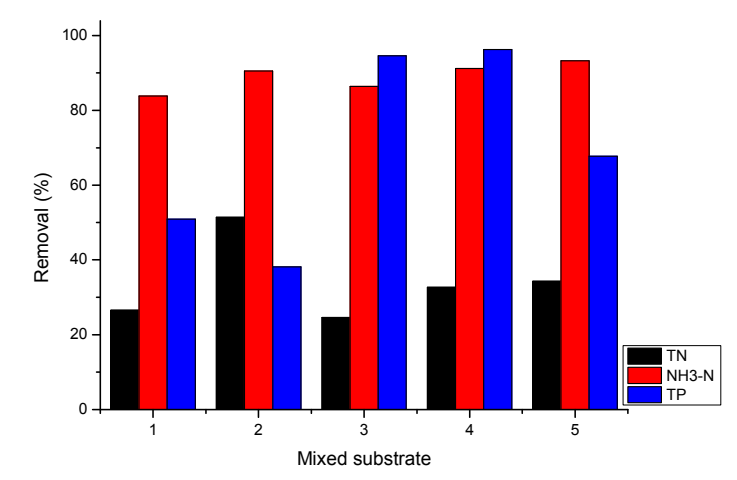

Fig.3 Removal effects of mixed substrates for nutrient

\section{Conclusion}

The capability of substrates in adsorption $\mathrm{TN}, \mathrm{NH}_{3}-\mathrm{N}, \mathrm{NO}_{3}-\mathrm{N}$, TP has been investigated by batch experiments. From the results, it can be concluded that zeolite is a very good adsorbent on nitrogen remove, followed by haydite and volcanic. The adsorption capacity of TP followed the order tire crumb $>$ vermiculite $>$ haydite $>$ volcanic $>$ zeolite. From the batch test of mixed substrates, it can be concluded that No. 4 mixed substrates (haydite $25 \%$, volcanic $25 \%$, zeolite $25 \%$, tire crumb $25 \%$ ) is the optimal mixed group of removing nutrient, the percentage removal of $\mathrm{TN}, \mathrm{NH}_{3}-\mathrm{N}, \mathrm{TP}$ is $32.68 \%, 91.22 \%, 96.23 \%$.

\section{Acknowledgments}

We would like to thank the Department of Water Environment, IWHR staff for their help with laboratory analyses, and graduate students for their guidance and assistance. This research is completed, under the financial aid of the National Science-technology Support Plan Projects "Practical technology research and development of restoration and reconstruction on damaged village ecosystem (2012BAJ21B03)."

\section{Reference}

[1] Liu Xiao, Huang Suiliang, Liu Xuegong. Characteristics of phosphorous adsorption on three substrates used in constructed wetland[J]. Chinese Journal of Environmental Engineering. 2012(10):3367-3372.

[2] Yeh N, Yeh P, Chang Y-H. Artificial floating islands for environmental improvement[J]. Renewable and Sustainable Energy Reviews. 2015,47(0):616-622.

[3] Deng Zhiqiang, Yan Baixing, Li huixu. Research progress of application of artificial floating beds technology [J]. Environmental Pollution \& Control. 2013(05):88-92.

[4] Lynch J, Fox LJ, Owen Jr JS, et al. Evaluation of commercial floating treatment wetland technologies for nutrient remediation of stormwater [J]. Ecological Engineering. 2015, 75(0):61-69.

[5] $\mathrm{Lu} \mathrm{H-L}, \mathrm{Ku} \mathrm{C}-\mathrm{R}$, Chang Y-H. Water quality improvement with artificial floating islands[J]. Ecological Engineering. 2015,74(0):371-375.

[6] Dong Bei, Liu Yang, Yang Ping. Research and application progress of rural domestic wastewater treatment with constructed wetlands $[\mathrm{J}]$. Water Resources Protection. 2011(02):80-86.

[7] Lu Shaoyong, Jin Xiangcan, Yu Gang. Nitrogen removal mechanism of constructed wetland[J]. Acta Ecologica Sinica. 2006(08):2670-2677.

[8] Huang Jinlou, Chen Qin, Xu Lianhuang. Problems and Countermeasures in the Application of Constructed Wetlands[J]. Environmrntal Science. 2013(01):401-408.

[9] White SA, Cousins MM. Floating treatment wetland aided remediation of nitrogen and 
phosphorus from simulated stormwater runoff [J]. Ecological Engineering. 2013,61, Part $\mathrm{A}(0): 207-215$.

[10]Borne KE. Floating treatment wetland influences on the fate and removal performance of phosphorus in stormwater retention ponds[J]. Ecological Engineering. 2014,69(0):76-82.

[11]Huang Jianhong, Mo Wenrui, Tian Senlin, et al. Ammonium nitrogen and phosphorus adsorption characteristics of three substrates in constructed wetland[J]. Applied Chemical Industry. 2012(05):774-780.

[12]Zhang Xiuwen, Li Fengmin, Lu Lun, et al. The adsorption properties of ten cw sybstrates on phosphorus[J]. Technology of Water Treatment. 2014(03):49-52

[13]K.D. Harmayani AHMFA. Adsorption of Nutrient from Stormwater Using Sawdust[J]. International Joyrnal of Environmental Science and Development. 2012,3:114-117.

[14]Leader JW, Dunne EJ, Reddy KR. Phosphorus sorbing materials: sorption dynamics and physicochemical characteristics[J]. Journal of environmental quality. 2008,37(1):174-181.

[15] Wan Zhengfen, Zhang Xueqing, Lu Shaoyong. The Adsorption and Desorption of Phosphorus by Nineteen Constructed Wetland Substrates[J]. Technology of Water Treatment. 2015(04): 35-39.

[16]Lisi RD, Park, J. K., Stier, J. C. Mitigating Nutrient Leaching with a Sub-Surface Drainage Layer of Granulated Tires[J]. Waste Management. 2004,24(8):831-839.

[17] Wang Gong, Wei Dongyang, Fang Xiaohang, et al. Study on the adsorption characteristics of nitrogen and phophorus on three substrates of constructed wetland[J]. Environmental Pollution \& Control. 2012(11):9-13.

[18]Liu Bo, Chen Yucheng, Wang Liwei, et al. Phosphorus adsorption characteristics of four substrates in constructed wetland $[\mathrm{J}]$. Chinese Journal of Environmental Engineering. 2010(01):44-48.

[19] Wanielista M, Chang N-B. Alternative Stormwater Sorption Media for the Control of Nutrients. Southwest Florida water management district, 2008.

[20] Shi Pengbo, Zhu Hongtao, Sun Dezhi. Removal efficiency of typical pollutants by different substrate combinations for constructed wetlands[J]. Acta Scientiae Circumstantiae. 2014(03): 704-711. 